\title{
Opioid Rotation
}

National Cancer Institute

\section{Source}

National Cancer Institute. Opioid Rotation. NCI Thesaurus. Code C21083.

Shifting from one opiate to another to maintain effectiveness in analgesia while minimizing the side-effect profile. 